Revista Mídia e Cotidiano

Artigo Seção Temática

Volume 12, Número 1, abril 2018

Submetido em: 01/03/2018

Aprovado em: 28/04/2018

\title{
AS ARENAS MIIIÁTICAS COMO PALCO DE LUTA DAS MINORIAS
}

\section{THE MEDIA ARENAS AS A STAGE FOR THE STRUGGLE OF MINORITIES}

\author{
Nelson Toledo FERREIRA ${ }^{1}$
}

\section{Resumo:}

Este artigo propõe uma reflexão teórica sobre a importância da articulação da representação política via arenas midiáticas, reforçando a visibilidade de demandas e de enfrentamento das minorias junto aos poderes instituídos. A representação política tradicional, moldada em processos eleitorais, perde espaço para um novo modelo, baseado em afinidades e experiências, consolidado pelos dispositivos midiáticos. Com isso, a mídia passa a ser um alicerce para a naturalização de determinados tipos de comportamentos e estilos de vida, reforçando a representação política dessas minorias. Não se trata de uma ruptura do modelo tradicional de representação política, mas uma complementação, potencializada pelas mídias digitais que garantem maior engajamento nas questões de grupos específicos.

Palavras-chave: Minorias; representação política; mídia.

\begin{abstract}
:
This article proposes a theoretical reflection about the importance of the articulation of political representation via media arenas, reinforcing the visibility of demands and confronting minorities with the instituted powers. Traditional political representation, modeled on electoral processes, loses space for a new model, based on affinities and experiences, consolidated by media devices. With this, the media becomes a foundation for the naturalization of certain types of behaviors and lifestyles, reinforcing the political representation of these minorities. This is not a rupture of the traditional model of political representation, but a complementation, enhanced by digital media that guarantee greater engagement in the issues of specific groups.
\end{abstract}

Keywords: Minorities; political representation; media.

\footnotetext{
${ }^{1}$ Doutor em Comunicação pela Universidade Federal Fluminense, atua em pesquisas nas áreas de comunicação política, representação política, minorias e cidadania.
} 


\section{míDiA

\section{INTRODUÇÃO}

As tecnologias da informação e comunicação (TICs) garantem aos segmentos minoritários suportes de visibilidade para reivindicação de suas demandas, de seus estilos de vida e de comportamentos que fogem aos padrões tradicionais da sociedade. Essa visibilidade tornou estratégica nas mobilizações, que muitas vezes começam com simples post nas redes sociais e acabam ganhando milhares de adeptos, chegando às ruas e mexendo com estruturas do poder. São as novas arenas de luta que se reconfiguram no dia a dia, repercutindo uma diversidade de manifestações em prol da cidadania.

As novas esferas públicas de debates, propiciadas pelas mídias digitais, podem ocasionar um aumento indiscriminado de vozes, gerando a cacofonia, uma situação na qual todos falam e ninguém escuta (BENKLER, apud MARTINO, 2014). Podem também servir como dispositivo de manipulação, radicalismo, intolerância, ódio, sectarismo e até fascismo de determinados grupos que se organizam via redes sociais, atentando contra a democracia e a pluralidade (LATTMAN-WELTMAN, 2015; CARVALHO, 2016). Todavia, há que se ressaltar a importância desses mesmos dispositivos tecnológicos na organização dos segmentos minoritários para fortalecer suas bandeiras de lutas, reivindicando a cidadania e a conquista dos seus direitos.

Este novo cenário político remete a um modelo de representação política que foge à lógica eleitoral, que sempre norteou as discussões sobre a conflituosa relação entre representantes e representados. Nas sociedades contemporâneas, um tipo peculiar de representação política está sendo moldado, baseado em afinidades e experiências compartilhadas pelos meios de comunicação impressos, eletrônicos e digitais. O engajamento e a pressão popular decorrentes de ações e práticas políticas de determinados grupos específicos reconfiguram um novo paradigma representativo desses novos agentes, que se inscrevem e interferem na lógica política formal.

A questão que se apresenta nesse artigo não é sobre uma ruptura do modelo tradicional de representação, mas uma complementação desse modelo alicerçado pela participação popular e o engajamento de setores da sociedade civil (associações de classe, movimentos sociais, ONG, grupos específicos) que ampliam seus espaços nas questões deliberativas dos segmentos e temáticas que atuam (AVRITZER, 2007), tendo os meios 
de comunicação como canais para potencializar sua legitimidade. Uma legitimidade que não é garantida formalmente pelo voto, mas pelo apoio às ideias e às experiências compartilhadas em defesa de interesses comuns com seus pares.

A mídia aparece, nos dias atuais, como um dispositivo que permite a pluralidade de vozes e de temáticas, forçando mutações importantes na organização da sociedade. Peter Dahlgren (2009), da Universidade de Lund, na Noruega, aponta para o aumento do potencial de engajamento cívico das mídias e dos ambientes digitais nos assuntos que dizem respeito à vida pública. De acordo com o autor, a internet permite que sejam desencadeadas ações em defesa de causas, interesses e estilos de vida, encontrando ressonância em uma forma específica de espaço. A participação política em rede passa a se desenvolver em torno de campos de interesse e de ação.

As petições públicas virtuais, por exemplo, potencializam mobilizações por ampliação dos direitos de mulheres, de negros, de homossexuais (na sua diversidade) e de outros públicos, que têm históricos de lutas e de exclusão social, defendendo projetos e políticas públicas. Muitos desses movimentos são acionados por algum episódio do cotidiano, em que se destaca a marginalização, a discriminação e o preconceito contra esses grupos, que eclodem via redes sociais, polemizando os debates e pressionando por mudanças, na medida em que influenciam a opinião pública e as tomadas de decisão dos poderes instituídos ${ }^{2}$.

$\mathrm{Na}$ última década, a revisão teórica sobre o conceito de representação política insere a mídia como principal mecanismo desta intrincada relação entre movimentos sociais, cidadania e política. Alguns estudos empíricos demonstram como os media têm uma influência sobre decisões de votos e posicionamentos políticos dos cidadãos (ALBUQUERQUE, 2012; ALDÉ, 2011; LEAL, 2012; GOMES, 2007; CHADWICK, 2006), no entanto, deixam lacunas para mostrar que da mesma forma que os

\footnotetext{
${ }^{2}$ A Avazz revela a força desses movimentos coletivos. Lançada em 2007, com a missão de mobilizar pessoas de quaisquer partes do mundo para agirem a favor de causas das mais diferentes temáticas, baseando-se nas assinaturas de suas petições online como dispositivo de pressão política sobre as autoridades formais constituídas dos diversos países. "O nosso modelo de mobilização online permite que milhares de ações individuais, apesar de pequenas, possam ser combinadas em uma poderosa força coletiva.(...) Operando em 15 línguas por uma equipe profissional em quatro continentes e voluntários de todo o planeta, a comunidade Avaaz se mobiliza assinando petições, financiando campanhas de anúncios, enviando e-mails e telefonando para governos, organizando protestos e eventos nas ruas, tudo isso para garantir que os valores e visões da sociedade civil global informem as decisões governamentais que afetam todos nós”. (AVAZZ, 2018) Disponível em: < https://secure.avaaz.org/page/po/about/>. Acesso em: 20 março 2018.
} 
representantes políticos utilizam os meios de comunicação para moldar comportamentos, garantir consenso e opiniões públicas favoráveis, grupos sociais específicos estão aprendendo a utilizá-los para potencializar suas vozes, reforçar suas insatisfações e orquestrar mobilizações políticas.

A proposta deste artigo é refletir teoricamente sobre a construção midiática da representação política, dialogando com alguns teóricos sobre o impacto dos meios de comunicação nesta constante e consolidada interface entre os campos político e midiático. As chamadas minorias, entendidas como aqueles segmentos que buscam potencializar suas vozes na sociedade, estão reforçando a mobilização popular em prol de seus direitos, utilizando agendamentos e enquadramentos midiáticos para levar suas questões à esfera política e provocar transformações na sociedade. E neste percurso, o conceito de representação política inaugura uma nova relação entre representados e representantes, que foge aos tradicionais cenários políticos eleitorais, destacando a participação e o engajamento político de importantes setores sociedade civil.

\section{DISCURSOS MIDIÁTICOS NA CONSTRUÇÃO DA VIDA COTIDIANA}

Os meios de comunicação ocupam uma posição privilegiada do ponto de vista de alcance social, tornando-se objetos importantes, não apenas porque são os grandes responsáveis pelo agendamento dos assuntos cotidianos, mas também porque, em alguma medida (que varia no tempo, no espaço e de acordo com a diversidade de recepções), podem ser capazes de afetar as visões de mundo e, em decorrência, os comportamentos sociais e políticos. O discurso midiático articula saberes e poderes, já que cria uma determinada percepção da realidade: os próprios modos de articular determinadas narrativas acabam por estabelecer versões sobre o que seria essa realidade. Os meios acabam por se constituir numa variável relevante para explicar fenômenos sociais, políticos e econômicos: logo, não podem ser esquecidos quando se trata de discutir os processos de posicionamentos das ideologias hegemônicas e contra-hegemônicas.

Com efeito, é através da linguagem que a realidade é socialmente absorvida pelos indivíduos, o que remete à importância do processo comunicacional. Refletir sobre o senso comum criado pela mídia nos leva à discussão sobre os aspectos da socialização 
dos sujeitos e a construção de valores, crenças e juízos, enraizados em etapas da sua vida. É a partir destes critérios subjetivos que os indivíduos decidem suas ações e comportamentos durante outras fases de seu desenvolvimento como um sujeito ativo na sociedade. Diante dessa perspectiva, é necessário pensar formas de pluralizar as vozes na sociedade para que sejam firmados discursos diferentes da cultura hegemônica, contribuindo para a inclusão de grupos marginalizados, vítimas de dogmas religiosos ultrapassados, machismo, racismo e outros tipos de discriminações arraigados na cultura de muitos povos. O embate midiático por meio da visibilidade das demandas que surgem desses segmentos sociais minoritários aparece como estratégico para uma nova construção discursiva: a criação de sensos comuns e a naturalização de comportamentos, estilos de vida e opções, reforçando novos espaços de atuação política.

Diante do exposto, os meios de comunicação acabam se tornando importantes canais de representação política por conseguirem com eficácia disseminar conteúdos simbólicos, priorizando determinadas temáticas em detrimento de outras, e, definindo um agendamento do que é importante para a sociedade por conta da sua visibilidade midiática. E a partir disso, outro processo se inicia, que é o enquadramento, "marcos interpretativos construídos socialmente, que permitem as pessoas atribuírem sentido aos acontecimentos e às situações sociais"3. A ênfase a determinadas palavras, imagens, metáforas e retóricas em um discurso acaba por legitimar determinadas ideias, obscurecendo outras menos visíveis nestas construções textuais e/ou imagéticas, construindo percepções direcionadas de realidade, de acordo com interesses de grupos.

Enquadrar é selecionar alguns aspectos de uma realidade percebida e torná-los mais salientes num texto comunicativo, de modo a promover uma definição de problema particular, uma interpretação causal, avaliação moral e ou recomendação de tratamento (ENTMAN apud SOARES, 2009, p.58).

Sabe-se que os discursos de determinadas instituições e/ou segmentos sociais organizados são também importantes fontes de agendamento, tendo uma postura ativa ou reativa em relação aos enquadramentos dos meios massivos na sociedade, buscando sensibilizá-los na tentativa de incluir ou excluir temáticas. Miguel (2003) aponta que

\footnotetext{
${ }^{3} \mathrm{O}$ conceito é baseado na obra Frame analysis, do sociólogo americano Erving Golffman (SOARES, 2009, p. 57)
} 
Os diversos grupos de interesse presentes na sociedade disputam a inclusão ou exclusão de temas na agenda, bem como sua hierarquização, mas quem ocupa a posição central são os meios de comunicação de massa, conforme tem demonstrado a ampla literatura sobre a chamada agenda-setting (definição de agenda). A mídia é, de longe, o principal mecanismo de difusão de conteúdos simbólicos nas sociedades contemporâneas e, uma vez que inclui o jornalismo, cumpre o papel de reunir e difundir as informações consideradas socialmente relevantes. (...) os grupos de interesses e mesmo os representantes eleitos, na medida em que desejam introduzir determinadas questões na agenda pública, têm de sensibilizar os meios de comunicação. (MIGUEL, 2003, p. 132)

Miguel acrescenta que "os meios são hoje o principal instrumento de difusão das visões do mundo e dos projetos políticos, sendo que neles se encontram as representações do mundo social, ligadas aos diversos grupos de interesse da sociedade" (MIGUEL, 2003). Sob esta ótica, várias investigações empíricas têm revelado como os meios de comunicação foram parciais em relação às disputas eleitorais nas últimas décadas e na construção de cenários de representação política ${ }^{4}$, apoiando candidatos comprometidos com a elite econômica do país para a manutenção de seus interesses. No entanto, percebese que apesar do inegável poder dos meios, esses não são tão definidores das questões políticas, como alguns teóricos apregoavam. Com as inovações tecnológicas e a disponibilidade maior de ofertas de comunicação, via uma infinidade de novas mídias digitais que os cidadãos têm acesso, novos discursos vêm sendo proferidos, oferecendo novas leituras da realidade. Os papéis dos receptores e dos emissores se confundem, na constante apropriação e reciclagem das mensagens informativas que chegam e que saem de suas redes sociais.

Diante dessa perspectiva, ocorrem embates discursivos em múltiplas arenas midiáticas, pluralizando vozes, demandas, opiniões que apontam para uma sociedade mais democrática, consolidando, com isso, uma abertura de espaços políticos para muitos segmentos que foram excluídos, historicamente, dos processos sociais e políticos. Mesmo que sejam registrados discursos de ódio, intolerância e preconceito, esses grupos que sempre foram marginalizados estão se posicionando discursivamente, questionando,

\footnotetext{
${ }^{4}$ O conceito de Cenário de Representação Política (CR-P) foi elaborado por Venício Artur de Lima, em 1994, como uma estrutura simbólica, contraditória e dinâmica, que assinala os limites os quais se dão os conflitos políticos. (...) lugar e objeto da articulação da hegemonia, no qual se refletem e se constroem os significados da política (SOARES, 2009, p. 157)
} 
confrontando e construindo espaços de vocalização de suas demandas, conseguindo ressonância e apoios políticos na sociedade.

\section{A MÍDIA COMO ENGRENAGEM DOS DEBATES SOBRE REPRESENTAÇÃO POLÍTICA}

Um marco teórico sobre representação política é o livro de Hanna Pitkin, The Concept of Representation, publicado em 1967, nos Estados Unidos. A publicação revelava, já naquela época, uma maneira inovadora para repensar o tema como uma atividade social, fugindo da noção ortodoxa até então empregada para designar a representação. E nessa reflexão, a importância dos embates discursivos para legitimar esta representação política aparece de forma incipiente. A autora categoriza a representação política em representação formalista, descritiva, simbólica e substantiva. A primeira enfatiza a noção de representação sob duas dimensões: por autorização prévia e por responsividade, ideias estas defendidas inicialmente por Hobbes e pelo modelo liberal, respectivamente. Já a segunda, dá ênfase à relação entre representantes e representados, como se o primeiro espelhasse por meio das semelhanças o segundo. No terceiro caso, leva em conta o significado que o representante tem para aqueles que estão sendo representados. E, finalmente, a representação substantiva referindo-se à substância do que é feito, ou seja, são as atividades dos representantes, as ações realizadas em nome e no interesse dos representados, é que são avaliadas.

Em todos os casos, observa-se que a representação política ultrapassa o cenário eleitoral para a legitimação do exercício do poder por determinados grupos. A concepção de representação política já traz consigo uma exigência de legitimação construída através de processos de identificação entre os representados com seus representantes, o que exige medidas eficazes para que ocorram estes sentimentos de pertencimento dos cidadãos a determinados grupos e não a outros, com demandas comuns, discursos comuns, percepções comuns.

Em meados de 90, Bernard Manin traz contribuições importantes para o tema da representação, fazendo uma análise da evolução das democracias representativas, buscando um denominador comum entre elas ao longo de suas histórias no que se referia 
à eleição dos representantes pelos governados, à independência parcial dos representantes, à liberdade de opinião pública e às decisões políticas tomadas após os debates. Sua principal crítica recai sobre o processo de seleção dos governantes pelas eleições, o que ele considerava um arranjo aristocrático das elites. Manin (1995) traz com sua teoria o debate sobre polêmica de que os meios de comunicação estariam substituindo os partidos políticos na mediação entre representantes e representados, reforçando a importância da liberdade da opinião pública neste processo. Com o autor, é reforçada a chamada democracia da audiência, a qual os líderes políticos tinham um apelo maior do que as ideologias dos seus respectivos partidos.

\begin{abstract}
(...) Em primeiro lugar, os canais de comunicação política afetam a natureza da relação de representação: os candidatos comunicam diretamente com seus eleitores através do rádio e da televisão, dispensando a mediação de uma rede partidária. A era dos ativistas, burocratas de partido ou "chefes políticos" já acabou. Por outro lado, a televisão realça e confere uma intensidade especial à personalidade dos candidatos. (...) o que estamos assistindo hoje em dia não é a um abandono dos princípios do governo representativo, mas a uma mudança do tipo de elite selecionada: uma nova elite está tomando o lugar dos ativistas e líderes de partido. A democracia de público é o reinado do "comunicador". O segundo fator determinante da situação atual são as novas condições em que os eleitos exercem o poder. Reagindo a estas mudanças, os candidatos e partidos são ênfase à individualidade dos políticos em detrimento das plataformas políticas (Ibid., pp. 22-23).
\end{abstract}

Essas transformações na sociedade marcaram um novo período, com características que redesenharam o cenário político. Com a intensa fragmentação dos segmentos sociais, novas bandeiras de lutas por direitos e por espaços políticos foram levantadas, embaralhando ainda mais a concepção de representação política. As bases que sustentaram os partidos políticos e suas representatividades começaram a perder espaço nessa luta simbólica, deixando de ser tão homogêneas e com demandas comuns. Com isso, os partidos políticos enfraqueceram nos seus posicionamentos ideológicos, uma vez que tinham como suporte principal as classes sociais para definições de suas representações políticas, repercutindo nos modelos de sistema político que defendiam.

Trata-se de um fenômeno mundial, inclusive na Europa com a forte tradição dos partidos políticos. Chadwick (2006) lembra que um dos principais argumentos para esta crise partidária é que as sociedades pós-industriais já não contam com classes sociais e grupos homogêneos que deram origem aos partidos nos séculos XIX e XX. “(...) como as sociedades tornaram-se fragmentadas, os partidos políticos têm visto suas bases sociais 
murcharem ou tornarem-se repletas de clivagens sociais". (Ibid., p. 145). O autor ainda reforça que os eleitores são agora muito mais propensos a flutuar livres de identificação partidária e a fazer avaliações mais racionais de plataformas políticas. Nisso, as identidades políticas parecem menos fixas, fazendo com que os cidadãos exijam formas mais flexíveis e complexas de expressar diferentes visões políticas e não veem os partidos como os únicos capazes de acomodar tais diversidades ideológicas (Ibid., p. 146).

Entram em cena, as organizações da sociedade civil e formas não eleitorais de representação, buscando potencializar as vozes de determinados segmentos, até então excluídos do processo político e da tomada de decisões, exigindo, com isso, que suas demandas fossem incorporadas nos debates e assegurassem novos direitos sociais e políticos. Neste contexto, a mídia reforça seu papel crucial na vocalização das demandas de grupos sociais específicos e de suas lutas por direitos na sociedade.

Outra pesquisadora que acrescenta novos elementos à discussão sobre representação política, com vínculos com a opinião pública e com a mídia é a italiana Nadia Urbinati. No seu trabalho Representative Democracy: principles and genealogy, publicado em 2002, Urbinati (2002) defendeu a representação política como fundamental para o funcionamento da democracia, baseando-se no discurso público que valoriza a política democrática, potencializando as vozes dos cidadãos em todo o processo político, não só na escolha dos seus representantes. Nessa perspectiva, Urbinati (Id.) considera a representação política vinculada ao estimulo à participação política e à expressão da vontade popular, transformando-se, assim, em uma forma de organização política. Para Urbinati (Id.), a representação política amplia a noção de participação, na medida em que considera que um caráter deliberativo permitiria uma constante recriação e aperfeiçoamento do que entendemos por democracia. A autora inclui nessa discussão a noção de advocacy, como uma vontade superior e apaixonada às causas e demandas dos seus constituintes com certa autonomia de julgamento, o que distancia representantes dos representados, reforçando a importância da representação política como mola propulsora dos regimes democráticos. Urbinati (Id.) faz uma defesa das expertises, que seriam portavozes aprimorados dos seus representantes, o que é questionado por alguns teóricos sobre a legitimidade desta prerrogativa. 
Em outros textos posteriores ao lançamento do seu livro, Urbinati (2006) reforça que a representação é cada vez mais entendida como um fator intrínseco para a constituição da opinião pública por meio de seu papel reflexivo (deliberação) bem como essencial para definição de vias de influência do Estado (Ibid., p. 2). A partir dessa discussão, destacam-se emergentes formas não eleitorais de representação. Na época atual o mundo está preenchido por atores extraterritoriais, que interferem em todo o processo de representação, como os movimentos sociais transnacionais, dentre outros. A autora ressalta que o desenvolvimento das sociedades contemporâneas afetadas pelo mercado, tecnologia e vasto volume de informações fez com que a ideia de representação chegasse a um ponto de ruptura. A ideia do Estado representando povos é parcial e serve, atualmente, apenas para algumas questões. Urbinati (2006) enfatiza que os discursos que fornecem razões de legitimidade são pluralizados e cada vez mais públicos; mesmo que a representação eleitoral continue a ser referência para o poder do Estado, nos dias atuais, os espaços para reivindicações de representação rompem seus limites e se tornam mais abertos e segmentados por temas e novos sujeitos. Nestas discussões, a mídia revela toda sua força como protagonista no cenário político contemporâneo.

Na virada do século XX para o XXI, a discussão sobre representação política reaparece através das instituições representativas como mediadoras entre o Estado e a sociedade, reforçando o papel da esfera pública nos debates. Também neste período começam a aparecer estudos que se concentram na inclusão e exclusão de grupos marginalizados, gerando novas formas de abordagem teórica sobre a representação (MENDONÇA, 2008; CHADWICK, 2006; AVRITZER, 2007). As instituições representativas passaram por mudanças importantes que forçaram a inclusão do caráter informal discursivo em uma esfera marcada pelo pluralismo e diversidade, como agentes que se auto-autorizam (ONGs, fundações, grupos de interesses) e entidades que representam (fóruns deliberativos, painéis, conferências temáticas). 


\title{
NOVOS SEGMENTOS DEMANDAM NOVAS FORMAS DE REPRESENTAÇÃO POLÍTICA
}

Young (2002), no seu livro Inclusion and democracry, traz para o debate uma nova abordagem sobre representação, tendo como foco principal o conceito de "perspectivas sociais", visando, principalmente, os chamados grupos minoritários que aparecem com mais força no cenário político, como mulheres, negros, homossexuais e outros. Por essa ótica, cada um dos novos segmentos que irrompem no tecido social, a partir da década de 90, tem perspectivas diferenciadas em relação a algumas temáticas, que são necessárias para serem incorporadas nas discussões políticas dos regimes democráticos atuais. Mais uma vez, os processos midiáticos reaparecem como mecanismos de visibilidade das demandas desses grupos.

Young (2006) aproxima suas análises de uma visão deliberacionista da democracia e da representação política tentando abarcar a inclusão social destes novos segmentos, pois a multiplicidade dos pontos de vistas ampliaria a noção de realidade e contribuiria para o processo democrático.

\begin{abstract}
Numa sociedade complexa e com milhões de pessoas a comunicação democrática consiste em discussões e decisões fluidas, sobrepostas e divergentes, dispersas tanto no espaço como no tempo. O que são relações comunicacionais inclusivas em tais sociedades fluidas, descentralizadas de massa? No contexto dessas sociedades as queixas que apontam o caráter excludente das normas de representação. As pessoas muitas vezes reclamam que os grupos sociais dos quais fazem parte ou com os quais tem afinidade não são devidamente representados nos organismos influentes de decisão, tais como legislaturas, comissões e conselhos, assim como nas respectivas coberturas dos meios de comunicação (Ibid., p. 140).
\end{abstract}

Mendonça (2008) aponta que as formas eleitorais de representação vinculadas a entidades da sociedade civil, apesar de carecerem de formas legais de autorização e prestação de contas, consegue uma legitimidade pelos efeitos de suas porosidades interacionais. $\mathrm{O}$ autor acredita que na medida em que ocorram os confrontos em diferentes contextos comunicativos, a prestação de contas se dá através de dispositivos discursivos. As tecnologias de informação e comunicação (TICs) potencializam esses discursos na sociedade reforçando as demandas e as reivindicações de segmentos ditos minoritários, e, consegue ainda persuadir e, consequentemente, adquirir novos adeptos e apoiadores. Nesta perspectiva, o conceito de representação se torna bem mais amplo e bem mais 
inclusivo, reforçando a tese de Pitkin, no final dos anos 60, que a ideia de representação é dinâmica e se altera de forma simultânea com as mutações na sociedade e nas instituições.

Avritzer (2007) dá um passo à frente nesta perspectiva dialógica consolidada pelo crescimento de instituições da sociedade civil quando constrói o conceito de representação política por afinidades. Apesar de seu texto original sobre o tema não fazer nenhuma menção à importância da comunicação neste entendimento sobre as transformações do conceito de representação política, o autor dá ênfase à consolidação de múltiplas soberanias, imbuídas nas representações eleitorais e não eleitorais, que traz para os debates os múltiplos discursos que passam a fazer parte da cena política, reforçando a tendência de criação de mecanismos de comunicação entre as partes.

O autor ressalta a presença cada vez mais marcante da sociedade civil nas políticas públicas em todo o mundo, a partir da especialização temática e da experiência, sejam os eleitos pela população para desempenharem funções em conselhos e fóruns deliberativos setoriais, sejam aqueles que são definidos no interior das associações civis, agregando interesses parciais e solidariedades. Mas o destaque fica por conta da visão do autor sobre uma antecipação do processo de representação política, legitimado não só pela ação, mas por um passado de defesas de temas, direitos ou bandeiras de lutas, na medida em que esta trajetória de participação destes agentes da sociedade civil (sejam indivíduos ou associações) os permitem denunciar, criticar e reivindicar em nome dos segmentos que representam. Este contorno político é que altera a concepção de representação política dos tradicionais moldes eleitorais para mecanismos mais sutis de afinidade, construída, paulatinamente, de forma contínua e monitorada, pela troca comunicativa entre estes novos atores que emergem na sociedade, nos seus diálogos com as instâncias formais de representação, como os partidos políticos.

(...) O importante em relação a esta forma de representação é que ela tem sua origem em uma escolha de atores da sociedade civil, decidida, frequentemente no interior de associações civis. Estas exercem o papel de criar afinidades intermediárias. (...) Ao agregarem estes interesses, elas propiciam uma forma de representação por escolha que não é uma representação eleitoral de indivíduos ou pessoas. A diferença entre a representação por afinidade e a eleitoral é que a primeira se legitima em uma identidade ou solidariedade parcial exercida anteriormente (AVRITZER, 2007, p. 458). 
Estas reformulações sobre a concepção de representação política na contemporaneidade abarcam questões relativas a uma pluralidade das clivagens sociais que exigem respostas da sociedade, bem como relativas às macrorrelações que se estabelecem entre os movimentos transnacionais de direitos humanos, de homossexuais, de negros, de mulheres e de outros grupos ditos minoritários. Mendonça (2008) lembra que estes novos representantes que surgem podem atuar nas esferas de tomadas de decisão participativa bem como exercer forte influência sobre os representantes eleitos e na opinião pública pela vocalização de certos discursos. O autor reforça que a proposta é alterar o foco da representação que sempre foi pautado em indivíduos e meios eleitorais para um processo de descentralização de poderes, incluindo a discussão sobre os movimentos sociais transnacionais, que caracterizam as sociedades contemporâneas.

\section{MINORIAS E SUAS DEMANDAS NO CENÁRIO POLÍTICO}

Os movimentos sociais que surgiram na década de 90 reforçam diferenciações de estilos de vidas e de comportamentos chamando a atenção para a ideia de que uma verdadeira democracia só se consolida a partir de uma convivência harmoniosa com a diferença, tendo como parâmetro básico que todos têm direitos de expressar plenamente enquanto cidadãos. Com o processo de globalização e o incremento das tecnologias de informação e comunicação (TICs) criando arenas discursivas de debates ${ }^{5}$, segmentos sociais até então excluídos das discussões políticas ganham mais força, somando-se aos movimentos de grupos similares, marginalizados socialmente, que eclodiram em todas as partes do mundo. Gays, lésbicas, transexuais, mulheres, negros, deficientes físicos, indígenas e tantos outros se aproveitam dos meios de comunicação para potencializar suas reivindicações e levar o debate da diferença à esfera pública, mesmo que ainda esbarrem

\footnotetext{
${ }^{5}$ Essa é uma das premissas de um dos principais pesquisadores norte-americanos das relações entre redes digitais e política, Yochai Benkler. O autor propõe a ideia da internet como uma "esfera pública conectada". "Para ele, se no passado, o custo de ser ouvido na esfera pública era consideravelmente alto, o que praticamente impedia o cidadão comum de participar com voz ativa dos debates públicos na mídia, a internet permite que novas vozes entrem em circulação, aumentando potencialmente a capacidade da sociedade civil de se manifestar. No seu livro The wealth of networks, Benkler trabalha com as possibilidades que a internet abre para a participação democrática das pessoas nas causas e debates de seu interesse. (...) Na Esfera Pública conectada, explica Benkler, a arquitetura da informação elimina, ou ao menos diminui consideravelmente, essa assimetria entre emissão e recepção, fazendo com que as pessoas possam dizer o que estão pensando em um espaço público” (BENKLER apud MARTINO, 2014, pp 112-113).
} 
na barreira do preconceito e até mesmo da engrenagem da produção noticiosa dos mass media.

Muniz Sodré (2005) discorre sobre Kant para explicar como os alemães entendem maioridade e menoridade, para revelar como é a noção de minoria na sociedade atual. "Maioridade é Mündigket, que implica literalmente a possibilidade de falar. Münd significa boca. Menoridade é Unmundighkeit, ou seja, a impossibilidade de falar. Menor é aquele que não tem acesso à fala plena" (Ibid., p. 11). Diante desta assertiva, a questão das minorias está mais no sentido de não ter voz na sociedade, de buscar espaços para que seus discursos mobilizadores sejam reconhecidos socialmente. Já Silverinha (2005) afirma que "os grupos minoritários passaram a constituir-se no espaço público democrático com base nas suas reivindicações políticas tocantes à diferença e à sua representação nos destinos coletivos" (p. 41).

Mesmo em uma sociedade cada vez mais plural e fragmentada, alguns segmentos sociais são excluídos do processo discursivo nas mídias. Nos jornais, telejornais e portais de notícias raramente se encontram espaços para se discutir cidadania, no sentido mais amplo destas demandas minoritárias. São poucas as notícias, as reportagens ou outros tipos de gênero jornalístico que discutem acessibilidade, racismo, intolerâncias a credo, a opções sexuais e nenhum outro assunto similar, que eclode na sociedade atual, por meio da leitura e do olhar dos próprios segmentos marginalizados, exigindo uma reverberação nas esferas pública e políticas para que ocorram transformações. Esta discussão remete à noção de "perspectivas sociais" proposto por Young (2002), quando reforça que este olhar diferenciado, construído através da produção de sentidos e significados de determinados segmentos sociais, ou seja, de perspectivas sociais intrínsecas a estes grupos, é crucial para o aprimoramento da democracia.

Correia (2009) afirma que a grande mídia intervém de forma crucial na configuração destes grupos, através de estratégias discursivas, na maioria das vezes, negativas, tais como, por exemplo, a metaforização dos imigrantes e da imigração como inquietante, comparando-os, por exemplo, a fenômenos naturais de forma pejorativa: "fluxo", "onda", "avalanche". O autor ainda cita a associação de minorias étnicas a conflitos de criminalidade e sua descrição como atores sociais conflituosos com 
representações sobre marginalidade e a perturbação da ordem, dentre outras formas discursivas tipificadas.

Esta intervenção do jornalismo é visível, até, ao nível dos critérios que são usados para selecionar os acontecimentos que irão ser transformados em notícia: os chamados valores-notícias. Quando olhados de perto é possível verificar como os valores-notícias se articulam com a proximidade cultural, proporcionando enquadramentos binários em que o ingroup e outgroup, grupo interno e grupo externo são representados em perspectiva pelos media, valorizando valores e visões do mundo do primeiro e diabolizando os valores e visões do mundo do segundo (Ibid., p. 120).

No entanto, apesar desta constatação empírica, há que se considerar um incremento de movimentos sociais de organizações da sociedade civil que estão forçando espaços diferenciados nesta lógica dos meios de comunicação, tentando reverter este quadro de tipificações e estereótipos que reforçam o preconceito e a discriminação.

Exemplos marcantes destas iniciativas são as paradas gays que se proliferam no mundo inteiro; são as aparições de mulheres seminuas, reforçando o orgulho e a identidade feminina, como os movimentos Femen ${ }^{6}$ e a Marcha das Vadias ${ }^{7}$, que têm núcleos espalhados em todo o mundo; são as transexuais que impõem suas presenças em esportes coletivos e em carreiras de modelo. Em suma, são indivíduos ou grupos organizados que apostam na visibilidade midiática como estratégia de posicionamento político. Nas redes sociais, o número de grupos que reforçam suas identidades e suas bandeiras de luta também é exemplar, como o COMPretas- Coletivo Mulheres Pretas ${ }^{8}$, que faz discussões sobre feminismo e racismo; o Trans Tornar ${ }^{9}$, que visa o empoderamento das transexuais, dentre outros, que mantém milhares de seguidores. As tecnologias de informação e comunicação (TICs) ampliam a visibilidade desses novos agentes, repercutindo seus movimentos e práticas sociais, e, com isso, construindo novas formas de representação política. É a beleza da democracia de ir às ruas, buscar a visibilidade midiática e mostrar que o orgulho identitário é a arma mais poderosa para conquistar espaços e fortalecer a pluralidade democrática.

\footnotetext{
${ }^{6}$ O grupo Femen tem sua origem na Ucrânia, em 2008, mas mantém grupos em vários países, inclusive no Brasil. Disponível em $<$ http://www.femenbrazil.com/> . Acesso em 20 março 2018.

${ }^{7}$ A Marcha das Vadias ou Marcha das Galdérias surgiu no Canadá, em 2011, o evento se internacionalizou, sendo realizado em várias partes do mundo, como no Brasil. Disponível em< ( http://www.marchadasvadias.org/> Acesso em: 20 março 2018.

${ }^{8}$ Disponível em< https://www.facebook.com/Compretas/. Acesso em: 10 abril 2018.

${ }^{9}$ Disponível em $<$ https://www.facebook.com/coletivotranstornar/. Acesso em 10 abril 2018.
} 


\section{CONSIDERAÇÕES FINAIS}

A sociedade vive um momento ímpar de organização dos grupos denominados minoritários, tendo a mídia com principal estratégia para potencializar suas vozes por demandas e direitos, cada vez mais específicos. Uma sociedade plural impõe que a concepção de representação política saia das amarras do processo eleitoral, permitindo o engajamento e a participação dos mais variados setores da sociedade nas questões políticas, buscando ter voz ativa nas decisões.

Os grupos sociais que são historicamente marginalizados já não esperam e nem se contentam mais com representantes oficiais, eleitos pelo voto, para que canalizem suas reivindicações. Estão cientes de que eles próprios precisam conquistar espaços políticos para promover as mudanças de mentalidade que engessam a sociedade, impedindo-a de se tornar plena e tolerante com a cidadania de todos, independentemente de credo, opção sexual, gênero, ideologia, etnia, necessidades especiais ou quaisquer tipos de diferenças. Mesmo que sociedade tenha registrado avanços de grupos conservadores e de extremadireita, que tentam impor suas ideologias e impedir conquistas das minorias, elas estão engajadas e disputam seus espaços políticos, principalmente nas arenas midiáticas que efetivam seus discursos e naturalizam seus modos de vida e de comportamentos.

A mídia é uma arena importante, um espaço onde as disputas discursivas devem ser realizadas e conquistadas. São através de vozes plurais e discursos diferenciados que a sociedade promoverá momentos de convivência e de possibilidades efetivamente democráticas. A velha e tradicional noção de que os enquadramentos midiáticos reforçavam apenas uma leitura hegemônica da sociedade, construída pelas elites econômicas e políticas, vem sendo testada e confrontada com releituras desta realidade, através da expressão de segmentos que sempre foram excluídos de se posicionarem politicamente e de revelarem suas perspectivas sociais, no sentindo proposto por Young (2002). É a partir do momento que a mídia divulga e potencializa outras vozes, criando novas correntes contra-hegemônicas, que o espaço público é oxigenado e começa a ser repensado, forçando transformações sociais e políticas.

Estamos assistindo, ainda de forma tímida, que a representação política começa a sair dos gabinetes e ser construída nas ruas, no discurso das redes sociais, dos blogs, dos 
microblogs, dos portais de notícias, dos aplicativos e de outros dispositivos tecnológicos.

Neste novo cenário, as mídias digitais alteram essa relação entre representantes e representados, tendo a visibilidade como a principal estratégia de enfrentamento e de posicionamentos políticos, forçando o pensar e o repensar que a diferença dos segmentos ditos minoritários não pode ser nunca confundida com inferioridade, pelo contrário, deve ser confundida com a palavra democracia.

\section{Referências}

ALBUQUERQUE, Afonso. O paralelismo político em questão. Revista Compolítica, v. 2, n. 1, $\begin{array}{lcccc}\text { ed. jan-jun, } & \text { ano } & 2012 . & \text { Disponível } & \text { em } \\ \text { http://compolitica.org/revista/index.php/revista/article/view/43 } & \text { Acesso em: } 15 \text { abril } 2018 .\end{array}$

ALDÉ, Alessandra. Internet e democracia: expectativas da comunicação em rede. Revista USP, São Paulo, nº 90, p.24-41, junho/agosto, 2011.

AVAZZ. Disponível em: <https://secure.avaaz.org/page/po/ > Acesso em: 20 março 2018.

AVRITZER, Leonardo. Sociedade Civil, Instituições Participativas e Representação: da autorização à legitimidade da ação. DADOS - Revista de Ciências Sociais, Rio de Janeiro, Vol. 50, no 3, 2007.

CARVALHO, C. Banalidade do mal em comentários de leitores na internet e a disseminação da intolerância. E-Compós, v.19, n.2, 2016.

CHADWICK, Andrew. Internet Politics: States, Citizens and New Communication Technologies. New York: Oxford University Press, 2006.

CORREIA, J. Carlos. Teoria e crítica do discurso noticioso - notas sobre o jornalismo e representações sociais. Portugal: LabCom, 2009.

DALHGREN, P. Media and political engagement. Cambridge: Cambridge University Press, 2009

FACEBOOK. COMPretas- Coletivo de Mulheres Pretas. Disponível em: $<$ https://www.facebook.com/Compretas/> Acesso em: 10 abril 2018

Coletivo Trans Tornar. Disponível em:

$<$ https://www.facebook.com/coletivotranstornar > Acesso em: 10 abril 2018.

FEMEN. Disponível em: < http://www.femenbrazil.com> Acesso em: 20 março 2018.

GOMES, Wilson. A transformação da política na era da comunicação de massa. $3^{\text {a }}$ edição. São Paulo: Paulus, 2007.

LATTMAN-WELTMAN, F. Democracia e revolução tecnológica em tempos de cólera: influência política midiática e radicalização militante. Trabajo presentado en el congreso de VI Compolítica. Rio de Janeiro, 2015.

LEAL, Paulo Roberto Figueira; ROSSINI, P. G. C. Relações entre representantes e representados no twitter: os perfis de presidentes latino-americanos e a construção de uma agenda de pesquisa. In: XXI Encontro Anual da Compós, 2012, Juiz de Fora. XXI Encontro Anual da Compós, 2012.

MANIN, Bernard. As metamorfoses do governo representativo. Revista Brasileira de Ciências Sociais, Anpocs,São Paulo, ano 10, $\mathrm{n}^{\circ}$ 29, 1995. Disponível em: $<$ http://www.anpocs.org.br/portal/publicacoes/rbcs 00 29/rbcs29 01.htm> Acesso em: $10 / 01 / 2018$ 
MARCHA DAS VADIAS. Disponível em $<$ http://www.marchadasvadias.org $>$ Acesso em: 20 março 2018.

MARTINO, Luís Mauro Sá. Teoria das Mídias Digitais : linguagens, ambientes, redes. Petrópolis: Vozes, 2014.

MENDONÇA, Ricardo Fabrino. Representation and deliberation in civil society. Brazilian Political Science Review, $\mathrm{n}^{\circ} 2$, p.117-137, $2008 . \quad$ Disponível em: $<$ http://www.bpsr.org.br/english/arquivos/BPSR v2 n2 dec2008 05.pdf.pdf $>$ Acesso em: $15 / 01 / 2018$.

MIGUEL, L. Felipe. Representação política em 3-D - elementos para uma teoria ampliada da representação política. Revista Brasileira de Ciências Sociais - Vol. 18, $\mathrm{n}^{0}$ 51, 2003. Disponível em: $<$ http://www.scielo.br/pdf/rbcsoc/v18n51/15989> Acesso em: 09/02/2018.

PITKIN, Hanna. The Concept of Representation. Berkeley: University of California Press, 1967.

Representation. In: BALL, Terence; FARR, James; HANSON, Russel (org). Political innovation and conceptual change. Cambrige: University Press, 1989.

SILVERINHA, Maria João. Democracia e reconhecimento: repensar o espaço público. In: PAIVA, Raquel; BARBALHO, Alexandre (org).Comunicação e cultura das minorias. São Paulo: Paulus, 2005.

SOARES, M. César. Representações, jornalismo e a esfera pública democrática. São Paulo: Cultura Acadêmica, 2009.

SODRÉ, Muniz. Por um conceito de minoria. In: PAIVA, Raquel; BARBALHO, Alexandre (org).Comunicação e cultura das minorias. São Paulo: Paulus, 2005.

URBINATI, N. O que torna uma representação democrática. Lua Nova, São Paulo, 2006. Disponível em http://www.scielo.br/pdf/ln/n67/a07n67.pdf. Acesso em: 20 março 2018.

. The concept of representation in contemporary democratic theory. Annual

Review of Political Science Vol. 11. 2002. Disponível em: http://www.annualreviews.org/doi/pdf/10.1146/annurev.polisci.11.053006.190533. Acesso em: 13 março 2018.

YOUNG, Iris Marion. Inclusion and Democration. Oxford: Oxford University Press, 2002.

Representação política, identidade e minorias. Trad. Alexandre Morales. Lua Nova, São Paulo, 2006. Disponível em: < http://www.scielo.br/pdf/ln/n67/a06n67.pdf/>. Acesso em: 10/01/2018. 